\title{
Clinical Insights into the Gastrointestinal Manifestations of COVID-19
}

\author{
Jonathan Kopel ${ }^{1} \cdot$ Abhilash Perisetti $^{2} \cdot$ Mahesh Gajendran $^{3} \cdot$ Umesha Boregowda $^{4} \cdot$ Hemant Goyal $^{5}(0)$
}

Received: 25 March 2020 / Accepted: 21 May 2020 / Published online: 23 May 2020

(c) Springer Science+Business Media, LLC, part of Springer Nature 2020

\begin{abstract}
The month of December 2019 became a critical part of the time of humanity when the first case of coronavirus disease 2019 (COVID-19) was reported in the Wuhan, Hubei Province in China. As of April 13th, 2020, there have been approximately 1.9 million cases and 199,000 deaths across the world, which were associated with COVID-19. The COVID-19 is the seventh coronavirus to be identified to infect humans. In the past, Severe Acute Respiratory Syndrome and Middle East Respiratory Syndrome were the two coronaviruses that infected humans with a high fatality, particularly among the elderly. Fatalities due to COVID-19 are higher in patients older than 50 years of age or those with multimorbid conditions. The COVID-19 is mainly transmitted through respiratory droplets, with the most common symptoms being high fever, cough, myalgia, atypical symptoms included sputum production, headache, hemoptysis and diarrhea. However, the incubation period can range from 2 to 14 days without any symptoms. It is particularly true with gastrointestinal (GI) symptoms in which patients can still shed the virus even after pulmonary symptoms have resolved. Given the high percentage of COVID-19 patients that present with GI symptoms (e.g., nausea and diarrhea), screening patients for GI symptoms remain essential. Recently, cases of fecal-oral transmission of COVID-19 have been confirmed in the USA and China, indicating that the virus can replicate in both the respiratory and digestive tract. Moreover, the epidemiology, clinical characteristics, diagnostic procedures, treatments and prevention of the gastrointestinal manifestations of COVID-19 remain to be elucidated.
\end{abstract}

Keywords Coronavirus · COVID-19 · Gastrointestinal symptoms · Gastroenterology · Pandemic

Hemant Goyal

doc.hemant@yahoo.com

Jonathan Kopel

jonathan.kopel@ttuhsc.edu

Abhilash Perisetti

abhilash.perisetti@gmail.com

Mahesh Gajendran

mahesh.gajendran@ttuhsc.edu

Umesha Boregowda

Umesha.boregowda@bassett.org

1 Texas Tech University Health Sciences Center, 3601 4th Street, Lubbock, TX 79430, USA

2 Department of Gastroenterology and Hepatology, University of Arkansas for Medical Sciences, Little Rock, AR, USA

3 Paul L. Foster School of Medicine, Texas Tech University Health Sciences Center El Paso, 5001 El Paso Drive, El Paso, TX 79905, USA

4 Department of Medicine, Bassett Medical Center, 1 Atwell Road, Cooperstown, NY 13326, USA

5 The Wright Center for Graduate Medical Education, 501 S. Washington Avenue, Scranton, PA 18503, USA

\section{Introduction}

The COVID-19 is a novel coronavirus with the first reported case in Wuhan, Hubei Province of China, in early December 2019. The infected patients presented with pneumonia from an unknown cause, and by December 2019, the World Health Organization (WHO) recognized these cases due to a potential virus. In March 2020, COVID-19 spread to 166 other countries with a declaration as a pandemic by WHO [1]. The coronaviruses (CoVs) belong to a large family of single-stranded, positive-sense RNA viruses that infect both humans and animals, causing several respiratory, gastrointestinal (GI), hepatic and neurologic diseases [2]. The CoVs can be further divided into four major groups: alpha-coronavirus, beta-coronavirus, gamma-coronavirus and deltacoronavirus [3]. However, there were only six human COVs that have been identified, including the alpha-CoVs HCoVsNL63 and HCoVs-229E and the beta-CoVs HCoVs-OC43, HCoVs-HKU1, Severe Acute Respiratory Syndrome-CoV (SARS-CoV) and Middle East Respiratory Syndrome-CoV 
(MERS-CoV) [4]. The COVID-19 is the seventh human $\mathrm{CoV}$ to be identified, which has continued to spread globally.

The COVID-19-related disease can lead to pneumonia, Acute Respiratory Distress Syndrome (ARDS) and congestive heart failure [2]. Although COVID-19-related fatality data continue to change rapidly, current estimates from China put the case fatality rate in men and women at $2.8 \%$ and $1.7 \%$, respectively. Infected patients $<50$ years of age have a fatality risk of $<0.5 \%$, while those $>70$ years old have a fatality up to $8 \%$ [5]. However, current estimates put the cumulative fatality for COVID-19 at 5.6\% (95\% CI 5.4-5.8) for China and $15.2 \%$ (12.5-17.9) outside of China [6]. Globally, the fatality rate for COVID-19 is estimated to be 5.7\% (5.5-5.9) [6]. A recent study on the epidemiology of COVID-19 found that the daily cumulative index (DCI) of COVID-19 cases was greatest in China (1320.85 per day), followed by Republic of Korea (78.78 per day), Iran (43.11 per day), Italy (30.62 per day), Bahrain (9.5 per day), Kuwait (9 per day) and Japan (5.11 per day) [7]. Furthermore, the overall fatality rate of COVID-19 was highest in Eastern Mediterranean regions $(6.7 \%, n=34)$, followed by Asia (3.4\%, $n=2861)$ and Europe $(2.1 \%, n=23 \%)$ [7]. However, these fatality data continue to changes as more cases appear in the USA and abroad.

Besides, patients with heart and lung diseases, diabetes, decompensated cirrhosis, HIV with low CD4 counts and other immunosuppressed patients are at higher risk for contracting COVID-19 and developed severe disease. The diagnosis of COVID-19 is performed by the combination of history and physical examination, reverse transcriptasepolymerase chain reaction (rt-PCR) analysis and computerized tomography (CT) scan. However, the CT scans have been found to have the highest specificity for the diagnosis of COVID-19, although this may increase healthcare costs and reduces time to start treatment to individuals suspected of COVID-19 [8]. Currently, prevention of the transmission of COVID-19 remains at paramount importance. Therefore, the Centers of Disease Control (CDC) has recommended frequent hand washing, social distancing, avoiding crowds and avoidance of touching the mouth, nose and eyes to prevent the spread of COVID-19 until a vaccine or novel treatment is approved [9].

COVID-19 is the disease caused by SARS-CoV-2 or COVID-19 virus. Current evidence indicates that COVID19 virus (or SARS-CoV-2) belongs to the beta-CoV group and shares $80 \%$ nucleotide identity at the genomic level with SARS-CoV [10]. Similar to other CoVs, COVID-19 is believed to have originated from bats and transferred to other intermediate hosts before being transmitted to humans [11]. In most cases, COVID-19 is transmitted through respiratory droplets [12]. Once an individual is infected with COVID-19, the most common symptoms are fever (98\%), cough $(76 \%)$, myalgia or fatigue $(44 \%)$, and sometimes atypical symptoms such as sputum (28\%), headache (8\%), hemoptysis (5\%) and diarrhea (3\%) are present [2]. However, a patient can harbor a virus for a period of 2-14 days without any symptoms [2]. This is especially true with GI symptoms in which patients can still shed the virus even after pulmonary symptoms have resolved [13]. Given the high percentage of COVID-19 patients that present with GI symptoms (diarrhea, nausea, etc.), screening these patients is essential. Therefore, pre-screening for COVID-19 should extend to asymptomatic individuals while keeping the GI manifestations in mind [9].

The main limitations of our current understanding of COVID-19 and its effects on the GI tract are primarily due to poor understanding of the effects of other CoVs on the GI tract. For SARS- and MERS-CoV, the mechanism of gastrointestinal entry remains unknown; however, COVID19 has shown a mechanism by which CoVs might infect and proliferate in the GI tract for a long time. Although the respiratory symptoms of CoVs are well-known, the GI symptoms and continual viral shedding in the feces are often overlooked. This review provides a comprehensive list of the GI symptoms, pathophysiology and mechanisms related to those symptoms, including the role of fecal shedding of COVID-19.

\section{COVID-19 and Gastrointestinal Symptoms}

Recently, cases of fecal-oral transmission of COVID-19 have been confirmed in the United States (US) and China, indicating that the virus can replicate in both respiratory and digestive tracts [14]. Furthermore, it is hypothesized that the virus can be re-transmitted by feces through aerosolization of viral-containing droplets; however, this has not been confirmed [14]. Interestingly, some patients with positive COVID-19 stool samples did not experience any GI symptoms, nor did it correlate with the severity of lung infection [13]. However, testing stool samples for COVID-19 may provide an alternative method for diagnosing COVID19 [13]. Furthermore, testing stool after a patient has been infected with COVID-19 may be necessary to monitor any GI complications, and the potential for fecal-oral transmission after respiratory symptoms has resolved. Specifically, $20 \%$ of COVID-19 patients have viral RNA that remains positive even after the negative conversion of viral RNA in the respiratory tract [15]. Therefore, it might be possible that COVID-19 can produce long-term changes to the GI tract anatomy and physiology even after the respiratory infection has passed [15]. It could happen for the gut-microbiome and gut-lung crosstalk with the COVID-19 genome, which has been observed with the influenza virus in the past [16]. A few patients with COVID-19 showed intestinal microbial 
dysbiosis with decreased probiotics, such as Lactobacillus and Bifidobacterium [17].

Among COVID-19 patients, GI symptoms, such as diarrhea (2-10.1\%), and nausea and vomiting (1-3.6\%), occur with modest frequency compared to the fever and pulmonary symptoms in most patients (Table 1) [18-20]. A recent study suggests that GI symptoms can be as high as 50\% (39.6-50\%, nausea (17.3\%), diarrhea (12.9\%), anorexia (12.2\%), abdominal pain $(5.8 \%)$, belching $(5 \%)$ and emesis $(5 \%)[9,21]$. This difference in the GI and pulmonary symptoms suggests differences in the COVID-19 viral tropism compared to SARS-CoV, MERS-CoV and influenza virus [22-24]. Although the pathogenesis is still being investigated, the first step of viral entry into the enterocytes occurs via the angiotensin-converting enzyme 2 (ACE2) protein, similar to SARS-CoV $[15,25,26]$. ACE-2 is a type- 1 transmembrane metallocarboxypeptidase that helps regulate blood pressure along with the ACE through the renin-angiotensin systems (RAS) [27]. The ACE-2 degrades Angiotensin II to generate
Angiotensin 1-7, thereby negatively regulating RAS [28, 29]. Although ACE-2 is expressed mostly in the vascular endothelial cells, the renal tubular epithelium and in Leydig cells in the testes, ACE-2 has also been detected in the lung, kidney and GI tract [30-32]. The SARS and MERS-CoV are also believed to use the ACE-2 and DDP4, respectively, to enter cells for viral replication and release [33, 34]. As shown in Fig. 1, the virus can then spread to other digestive organs, such as the liver, by using the same ACE2 enzyme [9]. Reports of COVID-19 presenting with abnormal liver chemistries were found to be as high as $20-30 \%$ [9].

\section{GI Manifestation of COVID-19, SARS and MERS}

Despite the limited information on COVID-19 and its GI symptoms, information from SARS-CoV and MERS-CoV provides some insights on the symptoms and disease severity from other CoVs. The MERS-CoV has shown to infect human primary intestinal epithelial cells, small intestine

Table 1 Gastrointestinal symptoms of COVID-19, SARS-CoV and MERS-CoV

\begin{tabular}{lllll}
\hline CoV & References & Symptoms & Frequency & Mechanism \\
\hline COVID-19 & {$[18-20]$} & Diarrhea and nausea and vomiting & $39.6 \%$ or 50\% & ACE2 receptor-mediated \\
SARS-CoV & {$[23,48-50]$} & $\begin{array}{c}\text { Diarrhea, nausea and vomiting, } \\
\text { and abdominal pain }\end{array}$ & $38.4 \%$ & ACE2 receptor-mediated \\
MERS-CoV & {$[22,46,47]$} & Vomiting and diarrhea & $25 \%$ & DDP4 receptor-mediated
\end{tabular}

SARS-CoV Severe Acute Respiratory Syndrome-CoV, MERS-CoV Middle East Respiratory Syndrome-CoV

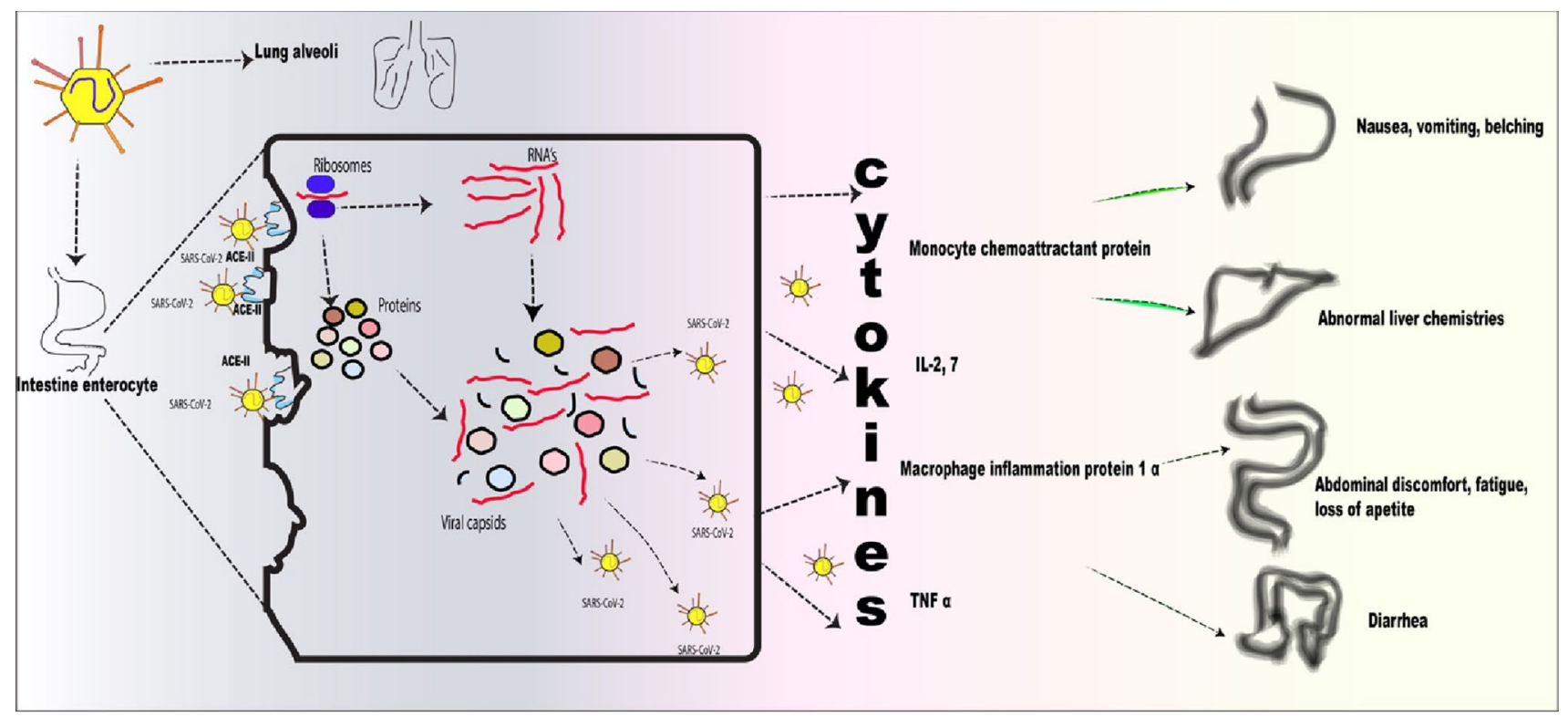

Fig. 1 Schematic representation of the effects of COVID-19 on enterocytes. COVID-19 enters the mucous membranes and gets access to enterocyte via ACEI II receptors. After entry into the cell, RNA and proteins are produced with the help of ribosomes. Viral capsids, RNA and protein combine to form multiple copies of
COVID-19. These viral particles exit the cell and lead to cytokine release (interleukin 2, 7, tumor necrosis factor [TNF] $\alpha$, macrophage and monocyte products). These cytokines mediate various effects on the gastrointestinal tract 
explants and intestinal organoids. It is also found to transmit via the fecal-oral route [35]. Given the prevalence of both MERS-CoV and COVID-19 in the Middle East, the co-infection of both coronaviruses through fecal-oral transmission remains a concern in countries with poor sanitation or healthcare infrastructure [36]. Patients infected with the MERS-CoV show almost a similar frequency of GI symptoms (35\%) as COVID-19 [22, 37, 38]. Specifically, the most common GI symptoms of MERS-CoV were diarrhea (22\%) and vomiting (17\%) [37]. Another study on MERS$\mathrm{CoV}$ patients showed the presence of GI symptoms in almost $25 \%$ of patients; the study found diarrhea (26\%), vomiting $(21 \%)$ and abdominal pain $(17 \%)$ being the most common GI symptoms [22].

SARS-CoV also showed a similar frequency of GI illnesses (38.4\%) to MERS-COV [32]. Furthermore, the frequency of diarrhea (19-50\%), nausea and vomiting (19.6\%) and abdominal pain (13\%) in SARS patients are similar to MERS- and COVID-19 [23, 39, 40]. Interestingly, some SARS patients $(8 \%)$ can present with diarrhea and fever without respiratory symptom; in most cases (20.3\%), SARS patients present with watery diarrhea [32]. The study also found that the SARS-CoV RNA can still be detected in the stool for more than 10 weeks after initial symptoms [32]. Therefore, COVID-19, like other CoVs, may continue to shed the virus through stool many weeks after the resolution of pulmonary symptoms. It is of a significant public health concern as poor water and sanitation practices could continue to spread COVID-19 in the community.

\section{Role of Cytokines in GI Manifestations of COVID-19}

Although no clinical studies have examined the release of the cytokine in the GI tract of COVID-19 patients. However, Th1 and Th2 cytokines cause hypocontractility and hypercontractility of inflamed intestinal smooth muscle through downregulating L-type $\mathrm{Ca}^{2+}$ channels and upregulating regulators of $\mathrm{G}$ protein-coupled receptors [41]. Furthermore, several cytokines such as interleukin-1 (IL-1), IL-33, IL-36, tumor necrosis factor- $\alpha$, IL- 6 and tumor necrosis factor-like cytokine $1 \mathrm{~A}$ all contribute to maintaining the integrity and function of the GI tract [42]. In COVID-19 patients with cytokine storm, elevations of IL-2, IL-7, granulocyte colony-stimulating factor, interferon- $\gamma$ inducible protein 10 , monocyte chemoattractant protein 1 , macrophage inflammatory protein 1- $\alpha$ and tumor necrosis factor- $\alpha$ were elevated [43]. Although these cases are rare, these cytokines may become elevated in mild or persistent COVID-19 cases [44]. For most COVID-19 patients, cytokines IL1- $\beta$, IL-1RA, IL-7, IL-8, IL-9, IL-10, FGF2, GCSF, GMCSF, IFN $\gamma$, IP10, MCP1, MIP1 $\alpha$, MIP1 $\beta$, PDGFB, TNF $\alpha$ and
VEGFA were also elevated [44]. Some of these cytokines have been previously shown to be involved in GI health and disease [45-50]. For example, IL-2 is a potent cytokine that binds to lymphocytes and macrophages to maintain and preserve intersinal epithelium after injury from mechanical stresses, infections or viruses [45]. Similarly, IL-10 TNF $\alpha$ are believed to maintain intestinal epithelium by termination of excess inflammatory responses after infections or cell death and survival mechanisms $[49,50]$. The elevation of these cytokines suggest an increased protective response to COVID0-19 infection and damage to the GI tact. Further studies are needed to indemnity the cytokines elevated in COVID-19 patients and how it may influence the health of the GI and respiratory tract through chronic alterations in cytokine expression and secretion.

\section{Laboratory and Imaging Studies}

White blood cell (WBC) counts vary in COVID-19 patients ranging from leukopenia, leukocytosis and lymphopenia; however, lymphopenia is the most common WBC derangement [5, 19, 51]. Elevated lactate dehydrogenase, ferritin and aminotransferase levels have also been observed [5, 19, 51]. As it is a viral infection, patients usually have normal procalcitonin levels; however, higher procalcitonin levels have been seen in patients admitted to the intensive care unit (ICU) care $[5,19,51]$. The COVID-19 patients typically present with bilateral ground-glass opacification with or without consolidations are consistent with viral pneumonia on chest CT scans $[52,53]$. Chest CT scans, together with rt-PCR testing, have a high sensitivity of $97 \%$ for detecting COVID-19 but at the expense of specificity being only $25 \%$ [54]. In patients with GI symptoms, the best test of COVID19 diagnosis appears to be the collection and analysis of stool samples $[13,14,17]$. Given the susceptibility of the GI tract to SARS-CoV-2 infection, it is also recommended to measure aminotransferase levels to evaluate the severity of the infection [9]. However, more studies of COVID-19 are needed to establish rigorous and reliable markers for evaluating GI injury.

\section{Treatment for GI Manifestation of COVID-19}

There are currently no approved treatment recommendations for GI manifestations of COVID-19 except for symptomatic and supportive care. The COVID-19 is currently being treated with antiviral agents that are under experimentation for effectiveness. These agents include chloroquine, chloroquine/hydroxychloroquine, remdesivir (novel nucleotide analog), lopinavir-ritonavir (protease inhibitor) and tocilizumab (IL-6 inhibitor) [55-68]. Each of these agents was 
shown to be effective against SARS-CoV in preliminary in vivo and in vitro studies; however, further human clinical trials are needed to assess the effectiveness of these agents $[69,70]$. Therefore, the medical community presumes that the same overlap might exist to counteract COVID-19 too. As of today, preventive measures (washing hands, social distancing, avoiding crowds, etc.) remain the only effective method for reducing the spread and severity of COVID-19.

\section{Fecal-Oral Transmission of COVID-19 and Endoscopy}

Currently, there is no evidence that the GI symptoms of elderly patients infected with COVID-19 are different from younger populations. Furthermore, given the potential risk of spread of the COVID-19 via fecal-oral transmission, all major American gastroenterological societies including American Association for the Study of Liver Diseases (AASLD), American Gastroenterological Association (AGA), American College of Gastroenterology (ACG) and American Society of Gastrointestinal Endoscopy (ASGE) have made recommendations for managing COVID-19 in the patients both in outpatient and endoscopy settings [9, 71]. They divided those procedures into "non-urgent/postpone" and "non-urgent/perform" depending on the need for the endoscopy. It has been strongly advised to reschedule nonurgent endoscopic procedures such as cancer evaluations, prosthetic removals and evaluation of significant symptoms [9, 71]. Furthermore, physicians are encouraged to screen patients using telemedicine for non-emergent procedures to decrease office visits for at-risk or infected patients and provide needed care to patients who are less willing or unable to travel. Besides, telemedicine between patients allows effective triage the urgent and non-urgent procedures, thereby reducing a patient's risk of being exposed to COVID-19. Deferral of the elective procedures is likely to decrease the risk of transmission of COVID-19 as luminal contents are frequently encountered during upper and lower endoscopies. Second, all personnel involved with endoscopic procedures should wear appropriate personal protective equipment (PPE) (gloves, mask, eye shield/goggles, face shields and gown) [9]. These protocols and PPE are strongly encouraged by the CDC and WHO [9]. With a shortage of medical supplies, it is also recommended that physicians extend the use or reuse of surgical masks and eye protection; however, reusing medical equipment may inadvertently increase COVID19 transmission or exposure [9]. Further investigation is needed to determine proper protective equipment protocols for COVID-19 infections.

Patients should be pre-screened again at the time of arrival to endoscopy center to determine whether they are at high risk if they report any history of fever or respiratory symptoms, family members or close contacts with similar symptoms, any contact with a confirmed case of COVID-19 and recent travel to a high-risk area [9]. High-risk patients with symptoms should be offered COVID-19 testing. Particular emphasis should be given to check the body temperature of patients arriving at the endoscopy center and avoid bringing patients older than 65 years to medical facilities unless necessary [9]. Furthermore, endoscopy units should inform patients at least $24 \mathrm{~h}$ before any procedure to discuss their risks of COVID-19, risks of endoscopy in viral transmission and appropriate intervention, including the postponement of the procedure.

Furthermore, the World Endoscopy Organization (WEO) suggests endoscopy centers should be at a biosafety level 2 (includes laboratories or medical facilities that work with agents associated with human diseases that pose a moderate health hazard) for all endoscopies. The biosafety level should be increased to level 3 (includes laboratories or medical facilities that work with microbes of either indigenous or exotic that cause serious or potentially lethal disease through inhalation) for COVID-19 patients [72]. As described by the British Society of Gastroenterology (BSG), the different biosafety levels minimize the transmission of COVID-19 and delay or "flatten" the outbreak curve of the infection, which prevents overwhelming the healthcare resources [73]. Therefore, the BSG recommends that endoscopic procedures only be performed in patients with acute upper GI bleeding, acute esophageal obstruction, endoscopic vacuum therapy for perforations/leaks, acute cholangitis/jaundice secondary to malignant/benign biliary obstruction, acute biliary pancreatitis, and/or cholangitis with stone and jaundice, infected pancreatic collections, urgent inpatient nutrition support and GI obstruction needing urgent decompression/stenting [73]. It is particularly important since these patients tend to have weaker immune systems and have a higher risk of infection [73].

\section{Conclusion}

The COVID-19 virus remains a global healthcare emergency as the number of cases and fatality continue to rise. As more information is being gathered, understanding of the virus will most likely improve with better diagnosis, prevention and treatment options for patients exposed or experiencing symptoms from the disease. However, the GI manifestations of COVID-19 pose a continuing challenge for the prevention of the virus spread. Physicians should monitor for GI symptoms in COVID-19-infected patients and examine whether the virus continues to remain in their stools after their respiratory symptoms have resolved. This knowledge may provide greater insight into preventing further infections and long-term complications arising from the COVID-19 and 
might help in policy-making to prevent the community from the virus spread.

\section{Acknowledgments None.}

Author's contribution AP, HG contributed to conception and design; all authors helped in reviewing the literature, drafting and critical revision and editing; and all authors contributed to final approval.

\section{Compliance with Ethical Standards}

Conflict of interest The authors have no commercial associations or sources of support that might pose a conflict of interest. All authors have made substantive contributions to the study, and all authors endorse the data and conclusions.

\section{References}

1. Gao QY, Chen YX, Fang JY. 2019 Novel coronavirus infection and gastrointestinal tract. J Dig Dis. 2020. https://doi. org/10.1111/1751-2980.12851.

2. Wu D, Wu T, Liu Q, Yang Z. The SARS-CoV-2 outbreak: what we know. Int J Infect Dis. 2020. https://doi.org/10.1016/j. ijid.2020.03.004.

3. Yang D, Leibowitz JL. The structure and functions of coronavirus genomic 3' and 5' ends. Virus Res. 2015;206:120-133. https://doi. org/10.1016/j.virusres.2015.02.025.

4. Zaki AM, van Boheemen S, Bestebroer TM, Osterhaus ADME, Fouchier RAM. Isolation of a novel coronavirus from a man with pneumonia in Saudi Arabia. N Engl J Med. 2012;367:1814-1820. https://doi.org/10.1056/nejmoa1211721.

5. Wang W, Tang J, Wei F. Updated understanding of the outbreak of 2019 novel coronavirus (2019-nCoV) in Wuhan, China. J Med Virol. 2020;92:441-447. https://doi.org/10.1002/jmv.25689.

6. Baud D, Qi X, Nielsen-Saines K, Musso D, Pomar L, Favre G. Real estimates of mortality following COVID-19 infection. Lancet Infect Dis. 2020. https://doi.org/10.1016/s1473-3099(20)30195-x.

7. Lai C-C, Wang C-Y, Wang Y-H, Hsueh S-C, Ko W-C, Hsueh P-R. Global epidemiology of coronavirus disease 2019: disease incidence, daily cumulative index, mortality, and their association with country healthcare resources and economic status. Int J Antimicrob Agents. 2020. https://doi.org/10.1016/j.ijantimica g.2020.105946.

8. Bai HX, Hsieh B, Xiong Z, et al. Performance of radiologists in differentiating COVID-19 from viral pneumonia on chest CT. Radiology. 2020. https://doi.org/10.1148/radiol.2020200823.

9. Bezerra JA, Pochapin MB, El-Serag HB, Vargo JJ. COVID-19 Clinical Insights for Our Community of Gastroenterologists and Gastroenterology Care Providers. Bethesda: American College of Gastroenterology; 2020.

10. Cheng ZJ, Shan J. 2019 Novel coronavirus: where we are and what we know. Infection. 2020. https://doi.org/10.1007/s1501 0-020-01401-y.

11. Perlman S. Another Decade, another coronavirus. $N$ Engl J Med. 2020;382:760-762. https://doi.org/10.1056/nejme2001126.

12. Jin Y-H, Cai L, Cheng Z-S, et al. A rapid advice guideline for the diagnosis and treatment of 2019 novel coronavirus (2019-nCoV) infected pneumonia (standard version). Mil Med Res. 2020;7:4. https://doi.org/10.1186/s40779-020-0233-6.

13. Zhang J, Wang S, Xue Y. Fecal specimen diagnosis 2019 novel coronavirus-infected pneumonia. J Med Virol. 2020. https://doi. org/10.1002/jmv.25742.
14. Holshue ML, DeBolt C, Lindquist S, et al. First case of 2019 novel coronavirus in the United States. $N$ Engl J Med. 2020;382:929-936. https://doi.org/10.1056/nejmoa2001191.

15. Xiao F, Tang M, Zheng X, Liu Y, Li X, Shan H. Evidence for gastrointestinal infection of SARS-CoV-2. Gastroenterology. 2020. https://doi.org/10.1053/j.gastro.2020.02.055.

16. Bradley KC, Finsterbusch K, Schnepf D, et al. Microbiotadriven tonic interferon signals in lung stromal cells protect from influenza virus infection. Cell Rep. 2019;28:245-256.e4. https ://doi.org/10.1016/j.celrep.2019.05.105.

17. Xu K, Cai H, Shen Y, et al. Management of corona virus disease-19 (COVID-19): the Zhejiang experience. J Zhejiang Univ. $2020 ; 49$.

18. Wu F, Zhao S, Yu B, et al. A new coronavirus associated with human respiratory disease in China. Nature. 2020;579:265-269. https://doi.org/10.1038/s41586-020-2008-3.

19. Chen N, Zhou M, Dong X, et al. Epidemiological and clinical characteristics of 99 cases of 2019 novel coronavirus pneumonia in Wuhan, China: a descriptive study. Lancet. 2020;395:507513. https://doi.org/10.1016/s0140-6736(20)30211-7.

20. Ji L-N, Chao S, Wang Y-J, et al. Clinical features of pediatric patients with COVID-19: a report of two family cluster cases. World J Pediatr. 2020. https://doi.org/10.1007/s12519-02000356-2.

21. Zhang J, Dong X, Cao Y, et al. Clinical characteristics of 140 patients infected with SARS-CoV-2 in Wuhan, China. Allergy. 2020. https://doi.org/10.1111/all.14238.

22. Assiri A, Al-Tawfiq JA, Al-Rabeeah AA, et al. Epidemiological, demographic, and clinical characteristics of 47 cases of Middle East respiratory syndrome coronavirus disease from Saudi Arabia: a descriptive study. Lancet Infect Dis. 2013;13:752-761. https://doi.org/10.1016/s1473-3099(13)70204-4.

23. Lee $\mathrm{N}$, Hui $\mathrm{D}, \mathrm{Wu} \mathrm{A}$, et al. A major outbreak of severe acute respiratory syndrome in Hong Kong. $N$ Engl $\mathrm{J} \mathrm{Med.}$ 2003;348:1986-1994. https://doi.org/10.1056/nejmoa030685.

24. Wang H, Xiao X, Lu J, et al. Factors associated with clinical outcome in 25 patients with avian influenza A (H7N9) infection in Guangzhou, China. BMC Infect Dis. 2016. https://doi. org/10.1186/s12879-016-1840-4.

25. Zhou P, Yang X-L, Wang X-G, et al. A pneumonia outbreak associated with a new coronavirus of probable bat origin. Nature. 2020;579:270-273. https://doi.org/10.1038/s4158 6-020-2012-7.

26. Hoffmann M, Kleine-Weber H, Schroeder S, et al. SARS-CoV-2 cell entry depends on ACE2 and TMPRSS2 and is blocked by a clinically proven protease inhibitor. Cell. 2020. https://doi. org/10.1016/j.cell.2020.02.052.

27. Riordan JF. Angiotensin-I-converting enzyme and its relatives. Genome Biol. 2003;4:225. https://doi.org/10.1186/ gb-2003-4-8-225.

28. Kuba K, Imai Y, Ohto-Nakanishi T, Penninger JM. Trilogy of ACE2: a peptidase in the renin-angiotensin system, a SARS receptor, and a partner for amino acid transporters. Pharmacol Ther. 2010;128:119-128. https://doi.org/10.1016/j.pharmthera .2010.06.003.

29. Tikellis C, Thomas MC. Angiotensin-converting enzyme 2 (ACE2) is a key modulator of the renin angiotensin system in health and disease. Int J Pept. 2012;2012:1-8. https://doi. org/10.1155/2012/256294.

30. Ksiazek TG, Erdman D, Goldsmith CS, et al. A novel coronavirus associated with severe acute respiratory syndrome. $N$ Engl J Med. 2003;348:1953-1966. https://doi.org/10.1056/NEJMoa030781.

31. Harmer D, Gilbert M, Borman R, Clark KL. Quantitative mRNA expression profiling of ACE 2, a novel homologue of angiotensin converting enzyme. FEBS Lett. 2002;532:107-110. https://doi. org/10.1016/s0014-5793(02)03640-2. 
32. Leung WK, To K, Chan PKS, et al. Enteric involvement of severe acute respiratory syndrome-associated coronavirus infection. Gastroenterology. 2003;125:1011-1017. https://doi.org/10.1016/j. gastro.2003.08.001.

33. Glowacka I, Bertram S, Herzog P, et al. Differential downregulation of ACE2 by the spike proteins of severe acute respiratory syndrome coronavirus and human coronavirus NL63. J Virol. 2010;84:1198. https://doi.org/10.1128/JVI.01248-09.

34. Li W, Moore MJ, Vasilieva N, et al. Angiotensin-converting enzyme 2 is a functional receptor for the SARS coronavirus. Nature. 2003;426:450-454. https://doi.org/10.1038/nature02145.

35. Zhou J, Li C, Zhao G, et al. Human intestinal tract serves as an alternative infection route for Middle East respiratory syndrome coronavirus. Sci Adv. 2017;3:eaao4966. https://doi.org/10.1126/ sciadv.aao4966.

36. Barry M, Al Amri M, Memish ZA. COVID-19 in the shadows of MERS-CoV in the Kingdom of Saudi Arabia. J Epidemiol Glob Health. 2020;10:1. https://doi.org/10.2991/jegh.k.200218.003.

37. Assiri A, McGeer A, Perl TM, et al. Hospital outbreak of Middle East respiratory syndrome coronavirus. $N$ Engl J Med. 2013;369:407-416. https://doi.org/10.1056/NEJMoa1306742.

38. Memish ZA, Zumla AI, Al-Hakeem RF, Al-Rabeeah AA, Stephens GM. Family cluster of Middle East Respiratory Syndrome coronavirus infections. N Engl J Med. 2013;368:2487-2494. https ://doi.org/10.1056/nejmoa1303729.

39. Tsang KW, Ho PL, Ooi GC, et al. A cluster of cases of severe acute respiratory syndrome in Hong Kong. $N$ Engl J Med. 2003;348:1977-1985. https://doi.org/10.1056/NEJMoa030666.

40. Tomlinson B, Cockram C. SARS: experience at Prince of Wales Hospital, Hong Kong. Lancet. 2003;361:1486-1487. https://doi. org/10.1016/s0140-6736(03)13218-7.

41. Akiho H, Ihara E, Motomura Y, Nakamura K. Cytokine-induced alterations of gastrointestinal motility in gastrointestinal disorders. World J Gastrointest Pathophysiol. 2011;2:72-81. https:// doi.org/10.4291/wjgp.v2.i5.72.

42. Bamias G, Dinarello CA, Rivera-Nieves J. Innate cytokines dictate the fate of acute intestinal inflammation. Gastroenterology. 2015;148:248-250. https://doi.org/10.1053/j.gastro.2014.11.013.

43. Mehta P, McAuley DF, Brown M, Sanchez E, Tattersall RS, Manson JJ. COVID-19: consider cytokine storm syndromes and immunosuppression. Lancet. 2020. https://doi.org/10.1016/s0140 $-6736(20) 30628-0$.

44. Rothan HA, Byrareddy SN. The epidemiology and pathogenesis of coronavirus disease (COVID-19) outbreak. J Autoimmun. 2020. https://doi.org/10.1016/j.jaut.2020.102433.

45. Dignass AU, Podolsky DK. Interleukin 2 modulates intestinal epithelial cell functionin vitro. Exp Cell Res. 1996;225:422-429. https://doi.org/10.1006/excr.1996.0193.

46. Dranoff G. Granulocyte-macrophage colony stimulating factor and inflammatory bowel disease: establishing a connection. Gastroenterology. 2011;141:28-31. https://doi.org/10.1053/j.gastr o.2011.05.023

47. $\mathrm{Xu} \mathrm{Y,} \mathrm{Hunt} \mathrm{NH,} \mathrm{Bao} \mathrm{S.} \mathrm{The} \mathrm{role} \mathrm{of} \mathrm{granulocyte} \mathrm{macrophage-}$ colony-stimulating factor in acute intestinal inflammation. Cell Res. 2008;18:1220-1229. https://doi.org/10.1038/cr.2008.310.

48. Shalapour S, Deiser K, Kühl AA, et al. Interleukin-7 links T lymphocyte and intestinal epithelial cell homeostasis. PLOS ONE. 2012;7:e31939. https://doi.org/10.1371/journal.pone.0031939.

49. Takada Y, Hisamatsu T, Kamada N, et al. Monocyte chemoattractant protein-1 contributes to gut homeostasis and intestinal inflammation by composition of IL-10 - producing regulatory macrophage subset. J Immunol. 2010;184:2671-2676. https:// doi.org/10.4049/jimmunol.0804012.

50. Ruder B, Atreya R, Becker C. Tumour necrosis factor alpha in intestinal homeostasis and gut related diseases. Int J Mol Sci. 2019;20:1887. https://doi.org/10.3390/ijms20081887.
51. Huang C, Wang Y, Li X, et al. Clinical features of patients infected with 2019 novel coronavirus in Wuhan, China. Lancet. 2020;395:497-506. https://doi.org/10.1016/s0140-6736(20)30183 -5 .

52. Shi H, Han X, Jiang N, et al. Radiological findings from 81 patients with COVID-19 pneumonia in Wuhan, China: a descriptive study. Lancet Infect Dis. 2020. https://doi.org/10.1016/s1473 -3099(20)30086-4.

53. Zhao W, Zhong Z, Xie X, Yu Q, Liu J. Relation between chest CT findings and clinical conditions of coronavirus disease (COVID19) pneumonia: a multicenter study. Am J Roentgenol.. 2020. https ://doi.org/10.2214/ajr.20.22976.

54. Ai T, Yang Z, Hou H, et al. Correlation of Chest CT and RTPCR testing in coronavirus disease 2019 (COVID-19) in China: a report of 1014 cases. Radiology. 2020. https://doi.org/10.1148/ radiol.2020200642.

55. Keyaerts E, Vijgen L, Maes P, Neyts J, Ranst MV. In vitro inhibition of severe acute respiratory syndrome coronavirus by chloroquine. Biochem Biophys Res Commun. 2004;323:264-268. https ://doi.org/10.1016/j.bbrc.2004.08.085.

56. Kono M, Tatsumi K, Imai AM, Saito K, Kuriyama T, Shirasawa $\mathrm{H}$. Inhibition of human coronavirus 229E infection in human epithelial lung cells (L132) by chloroquine: involvement of p38 MAPK and ERK. Antiviral Res. 2008;77:150-152. https://doi. org/10.1016/j.antiviral.2007.10.011.

57. Keyaerts E, Li S, Vijgen L, et al. Antiviral activity of chloroquine against human coronavirus OC43 infection in newborn mice. Antimicrob Agents Chemother. 2009;53:3416-3421. https://doi. org/10.1128/aac.01509-08.

58. Minodier L, Masse S, Capai L, et al. Clinical and virological factors associated with gastrointestinal symptoms in patients with acute respiratory infection: a two-year prospective study in general practice medicine. BMC Infect Dis. 2017. https://doi.org/10.1186/ s12879-017-2823-9.

59. Arbour N, Ekandé S, Côté G, et al. Persistent infection of human oligodendrocytic and neuroglial cell lines by human coronavirus 229E. J Virol. 1999;73:3326-3337. https://doi.org/10.1128/ jvi.73.4.3326-3337.1999.

60. Jo Stine M. Intussusception in a premature infant simulating neonatal necrotizing enterocolitis. Arch Pediatr Adolesc Med. 1982;136:76. https://doi.org/10.1001/archpedi.1982.0397037007 8023.

61. Jevšnik M, Steyer A, Zrim T, et al. Detection of human coronaviruses in simultaneously collected stool samples and nasopharyngeal swabs from hospitalized children with acute gastroenteritis. Virol J. 2013. https://doi.org/10.1186/1743-422x-10-46.

62. Risku M, Lappalainen S, Räsänen S, Vesikari T. Detection of human coronaviruses in children with acute gastroenteritis. J Clin Virol. 2010;48:27-30. https://doi.org/10.1016/j.jcv.2010.02.013.

63. Jacomy H, Talbot PJ. Vacuolating encephalitis in mice infected by human coronavirus OC43. Virology. 2003;315:20-33. https:// doi.org/10.1016/s0042-6822(03)00323-4.

64. Ann Yeh E, Collins A, Cohen ME, Duffner PK, Faden H. Detection of coronavirus in the central nervous system of a child with acute disseminated encephalomyelitis. Pediatrics. 2003;113:e73e76. https://doi.org/10.1542/peds.113.1.e73.

65. Morfopoulou S, Brown JR, Davies EG, et al. Human coronavirus OC43 associated with fatal encephalitis. $N$ Engl J Med. 2016;375:497-498. https://doi.org/10.1056/nejmc1509458.

66. Houtman JJ, Fleming JO. Pathogenesis of mouse hepatitis virusinduced demyelination. J Neurovirol. 1996;2:361-376. https://doi. org/10.3109/13550289609146902.

67. Boucher A, Desforges M, Duquette P, Talbot PJ. Long-term human coronavirus-myelin cross-reactive T-cell clones derived from multiple sclerosis patients. Clin Immunol. 2007;123:258267. https://doi.org/10.1016/j.clim.2007.02.002. 
68. Arbour N, Day R, Newcombe J, Talbot PJ. Neuroinvasion by human respiratory coronaviruses. J Virol. 2000;74:8913-8921. https://doi.org/10.1128/jvi.74.19.8913-8921.2000.

69. Ahn D-G, Shin H-J, Kim M-H, et al. Current status of epidemiology, diagnosis, therapeutics, and vaccines for novel coronavirus disease 2019 (COVID-19). J Microbiol Biotechnol. 2020;30:313324. https://doi.org/10.4014/jmb.2003.03011.

70. Sanders JM, Monogue ML, Jodlowski TZ, Pharmacologic Cutrell JB. Treatments for coronavirus disease 2019 (COVID-19). JAMA. 2020. https://doi.org/10.1001/jama.2020.6019.

71. Soetikno R, Teoh AY, Kaltenbach T, et al. Considerations in performing endoscopy during the COVID-19 pandemic. Gastrointest Endosc. 2020. https://doi.org/10.1016/j.gie.2020.03.3758.

72. Yafei Z, Xiaodan Z, Lan L, Hongling W, Qiu Z. Suggestions of infection prevention and control in digestive endoscopy during current 2019-nCoV pneumonia outbreak in Wuhan, Hubei Province, China. Endoscopy. 2020;52:312-314.

73. Endoscopy activity and COVID-19: BSG and JAG guidance. Brit Soc Gastroenterol. 2020. https://www.bsg.org.uk/covid-19advice/endoscopy-activity-and-covid-19-bsg-and-jag-guidance. Accessed 10 Apr 2020.

Publisher's Note Springer Nature remains neutral with regard to jurisdictional claims in published maps and institutional affiliations. 